\title{
Soil Moisture Mapping at Paddy Field in Indramayu Residence Using Landsat 8 OLI/TIRS
}

\author{
Mochamad Firman Ghazali ${ }^{1,3,4}$, Tri Muji Susantoro', ${ }^{1,5}$, Ketut Wikantika' ${ }^{1,2,3^{*}}$, Agung Budi Harto ${ }^{1,2}$, Rian Nurtyawan' \\ ${ }^{1}$ Center for Remote Sensing, Bandung Institute of Technology (CRS-ITB), Bandung, Indonesia \\ ${ }^{2}$ Remote Sensing and GIS Research Group, Faculty of Earth Science and Technology, Bandung Institute of Technology, Bandung, \\ Indonesia \\ ${ }^{3}$ ForMIND Institute (Indonesian Young Researcher Forum), Bandung, Indonesia \\ ${ }^{4}$ Geodesy and Geomatics Engineering, Faculty of Engineering, University of Lampung, Lampung, Indonesia \\ ${ }^{5}$ Research and Development Center for Oil and Gas Technology "LEMIGAS", Ministry of Energy and Mineral Resources, Jakarta, \\ Indonesia
}

ARTICLE INFO

Article history:

Received September 1, 2018

Received in revised form September 24, 2019

Accepted November 9, 2019

\section{KEYWORDS:}

Soil Moisture,

Landsat 8,

NDWI,

NDVI,

Land Surface Temperature,

Linear Soil Moisture,

Tasseled Cap Transformation

\begin{abstract}
Drought monitoring is important for the paddy planting planning. Remote sensing is one tool can be used for it. Paddy field monitoring based on the soil moisture gives much knowledge related to the water content in the soil. Soil moisture analysis in this study is using Normalized Different Water Index (NDWI), Linear Soil Moisture (LSM), and Tasseled Cap. Soil moisture change could explain based on calculation results of NDWI, Linear Soil Moisture (LSM), and Tasseled Cap Transformation (TCT). Based on the results has explained that the driest year occurs in 2015 and June 2016 has a higher soil moisture. Comparison with the radar shows that the results of soil moisture analysis with Landsat was effective can be used with results relatively close to the radar results.
\end{abstract}

\section{Introduction}

Indramayu is one district in West Java Province that spread out along to the north coast of Java. This district often experiences drought (Darojati 2015). Drought is a serious situation of the natural hazard causing the significant loss to crops production, water supplies and livestock (Rojas et al. 2011). It expected to increase in frequency and severity due to global warming (Li et al. 2015). This becomes one of the problems in order to maintain the rice production to ensure food sufficiency, especially in Indramayu district. According to the news in the local newspaper named "Pikiran Rakyat" that written on August 30th, 2017, the paddy field area in Indramayu district has suffered from the water supply. It causes the paddy plants to fail to harvest.

Drought monitoring is important for the paddy rice cultivation. Drought is a function of water content in the soil which is depends on the water supply from the rainfall, soil types and the evapotranspiration. Particularly in paddy rice cultivation, maintain the water supply and keep the soil moisture in a proper

\footnotetext{
* Corresponding Author

E-mail Address: wikantika.ketut@gmail.com
}

condition may lead into the a good yield. As a leading technology in earth monitoring, remote sensing can be used for understanding, monitoring of drought status in paddy rice field. Remote sensing data for drought monitoring such as Landsat is often used to monitor both in the bare land and agriculture land. It is related to the soil moisture and the surface temperature identification. Especially in the surface temperature, researchers conducted the study derived from optical satellite sensor (thermal data) to accommodate the temperature factor (Zeng et al. 2004; Wang 2009; Pandolfo et al. 2017). Many researchers studied the soil moisture in the dry land or in the semi-dry land. The supervision of soil moisture is the key factor for success the planting of paddy field and another plant. It is mainly influenced by the amount of rainfall and water from groundwater or irrigation.

There are several methods for drought monitoring that are widely used, including the Palmer Drought Severity Index (PDSI) (Palmer 1965), the Standardized Precipitation Index (SPI) (McKee et al. 1993), The Standardized Precipitation Evapotranspiration Index (SPEI) (Vicente-Serrano et al. 2010), Vegetation Health Index (VHI) (Kogan 1995; 
Sparavigna 2015), and Temperature Condition Index (TCI) (Kogan 1995). Especially in paddy field area, the drought monitoring can be used Linear Soil Moisture (LSM) as a simple regression between Normalized Difference Vegetation Index (NDVI) and Land Surface Temperature (LST) (Zeng et al. 2004; Wang 2009; Pandolfo et al. 2017) and the Normalized Difference Water Index (NDWI) (Gao 1996; McFeeters 1996) and Tasseled Cap (Baig et al. 2014).

Paddy field monitoring based on the soil moisture gives much knowledge related to the water content in the soil. It is not only to support paddy plant to grow but also allow for creation the mud and it is making the root growth better. Root is an important factor for resulting the best yield in the harvest of the paddy field. When the root is growing better, it will give a significant result of the yields. The depth of mud has to influence of the root growth. In the thick mud, it possible to make the root growth well without the barrier, but in the thin mud, the root growth in the limited area (De Datta 1981). The depth of mud level is correlated to the groundwater in the paddy field (Figure 1).

The purpose of this study is to monitor the soil moisture condition in paddy field area as an impact of drought. In this study, soil moisture condition in Indramayu District is monitored with remote sensing data of Landsat 8 OLI/TIRS.

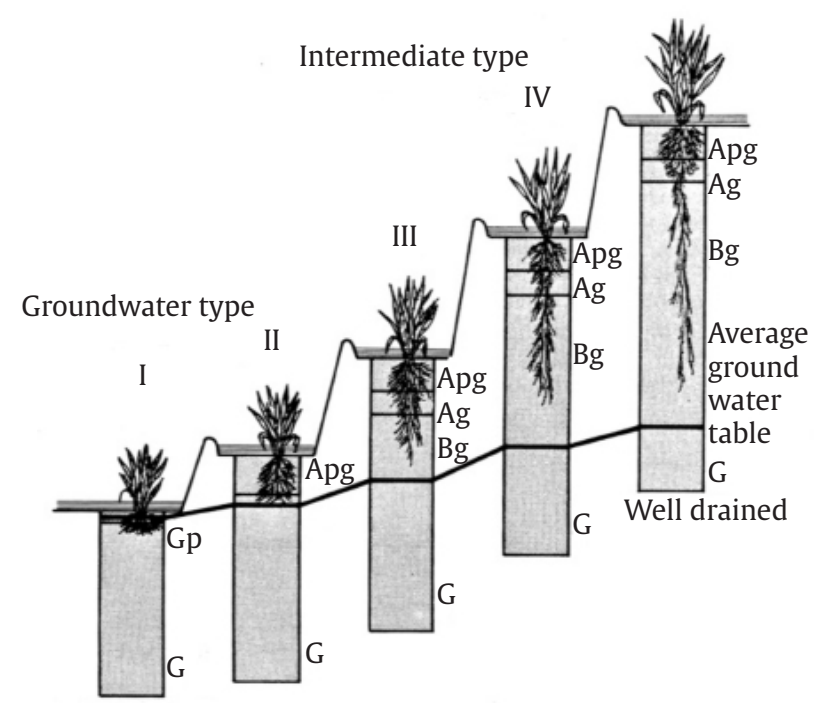

Very poorly drained

Figure 1. The correlation of the root growth of paddy based on the groundwater depth and the depth level of mud (De Datta 1981)

\section{Materials and Methods}

\subsection{Study Area}

Indramayu District is located in the northern part of West Java province. This district is bordered by the Java Sea to the north, Subang District in the west, Sumedang District in the south, and Majalengka and Cirebon District in the east. Indramayu has a large paddy field area. According to the fieldwork, the northern part of paddy field is located near the Java Sea. Which is in some area are influenced by seawater intrusion. Generally, the irrigation of paddy field area is using water from Rentang dam, mainly in the middle and southern parts areas. This is the dam system that built-in Ci Manuk River. The location of the study can be seen in Figure 2 .

\subsection{Data}

This research is using a Landsat 8 OLI/TIRS multitemporal data. Five series of Landsat $8 \mathrm{OLI} /$ TIRS were acquired from the free global Landsat Data (http://earthexplorer.usgs.gov/). The data series used from 2015 to 2017. In this case, we used Landsat 8 data that was recorded in a drought season, especially in March to June. The reason is to understand the characteristics of water losses in the study area that focused in the paddy field. The whole data used in this research is provided in Table 1.

\subsection{Pre-processing}

The Landsat 8 observatory operates in near circular, near-polar sun-synchronous with $705 \mathrm{~km}$ altitude at the equator. It has a 16-day ground track repeat cycle (Ali et al. 2017). The value recorded in the Landsat data not only the reflected or emitted radiation from the surface, but also the radiation scattered and emitted by the atmosphere. In this cases to achieve these values radiometric calibration and correction must be applied (Humboldt State University 2016).

Landsat 8 OLI/TIRS band data can be converted to Top of Atmosphere (ToA) spectral radiance using the radiance rescaling factors provided in the metadata file (USGS 2017). The equation is defined as follows:

$$
\begin{aligned}
& \rho \lambda^{\prime}=M \rho^{*} Q \text { cal }+A \rho \\
& \rho \lambda=\rho \lambda^{\prime} / \sin S E
\end{aligned}
$$




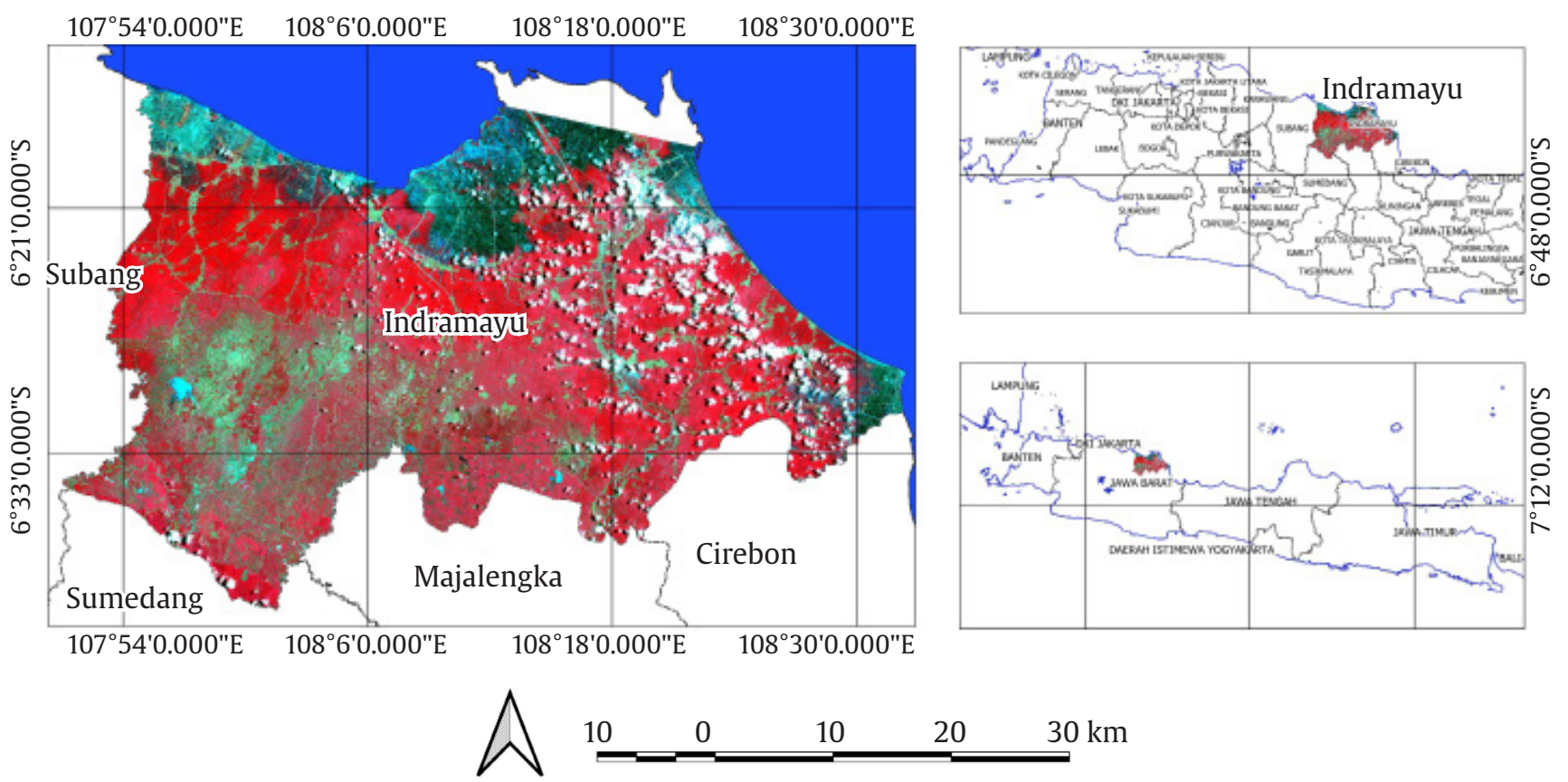

Figure 2. Study area in north of West Java Province with subset of Landsat 8 OLI/TIRS

Table 1. Landsat 8 OLI/TIRS data used in this study

\begin{tabular}{ll}
\hline File name of Landsat 8 data & Acquisition date \\
\hline LC81210652015076LGN00 & March-2015 \\
LC81210652015140LGN00 & May-2015 \\
LC81210652016159LGN00 & June-2016 \\
LC81210652016223LGN01 & August-2016 \\
LC81210652017145LGN00 & March-2017 \\
\hline
\end{tabular}

where,

$\rho \lambda^{\prime} \quad$ :Top of Atmosphere(ToA)planetary reflectance without correction for the solar angle

$\mathrm{M} \rho \quad$ : band specific multiplicative rescaling factor from the metadata

Qcal : quantized and calibrated standard product pixel values (digital number)

A $\quad$ : band specific additive rescaling factor from the metadata

$\rho \lambda \quad$ :ToA planetary reflectance with correction for the solar angle

SE : local sun elevation angle

\subsection{Processing and Analysis}

Soil moisture analysis in this study are using Normalized Different Water Index (NDWI) (Gao 1996; McFeeters 1996), Linear Soil Moisture (LSM) (Zeng et al. 2004; Wang 2009; Pandolfo et al. 2017), and Tasseled Cap (Baig et al. 2014).

\subsubsection{NDWI}

Normalized Different Water Index (NDWI), originally it used a combination of reflectance from near-infrared
(NIR) band and shortwave infrared (SWIR) band (GAO 1996), and a combination of reflectance from nearinfrared (NIR) band and green band (McFeeters 1996). The Equation (3) is used to estimate the water content in the leaves. In this case, it is possible to determine water content in paddy leaves in the paddy field. The Equation (4) is used to understand the water content in the water bodies. In this case, water bodies mean irrigation system used in the paddy field, Ci Manuk river stream, Ci Pancuh lake, and Rentang dam. The equation are defined as follows:

$$
\begin{aligned}
& N D W I=\frac{(\rho N I R-\rho S W I R)}{(\rho N I R+\rho S W I R)} \\
& N D W I=\frac{(\rho \text { Green }-\rho N I R)}{(\rho \text { Green }+\rho \text { NIR })}
\end{aligned}
$$

\subsubsection{Linear Soil Moisture}

Linear soil moisture is a method for estimate a soil moisture condition using a regression between NDVI and LST. We proposed a new method to estimate soil moisture call as Linear Soil Moisture (LSM). This is a simple method than (Zeng et al. 2004; Wang 2009; Pandolfo et al. 2017). This equation is to explain that the condition of paddy depends on the water content in the soil. The high amount of water will give the lowest temperature, and paddy will grow well. In other situation, the high temperature caused the paddy will not grow well. The formula of NDVI is using reflectance value of near-infrared (NIR) band and red band, and 
LST is using thermal band 10 of Landsat 8. NDVI and LST are defined as follows:

$$
N D W I=\frac{(\rho n i r-\rho r e d)}{(\rho n i r+\rho r e d)}
$$

where $\rho$ nir is the near infrared band reflectance and pred is red band reflectance.

$$
T(C)=K 2 / \ln (K 1 / L \lambda+1)-273.15
$$

where $\mathrm{K} 1=$ Thermal Constant Band 10 and $\mathrm{K} 2=$ Thermal Constant Band 10.

Physical background used as the reference on this equation is paddy needs to grow well as good as the water content in the soil. The high amount of water will give the lowest temperature and paddy will growth well. In other situation, the high level of temperature will occur in the area without paddy. The area with paddy represents the highest NDVI has the lowest temperature on LST. The lowest NDVI means there is no paddy in the area has the highest temperature. This situation gives a relationship between NDVI and LST or between the paddy and the temperature. Table 2 below provides five regression equation for calculating soil moisture. All the calculation results were normalized to 0 to 1 , to provide the same level of soil moisture and classified as $0=$ low, $0.5=$ moderate, and $1=$ high .

\subsubsection{Tasseled Cap Transformation}

The Tasseled Cap Transformation (TCT) is a technique commonly used in land cover mapping or other classification projects. It takes the linear combination of satellite imagery bands and a specialized coefficient

Tabel 2. Regression equation for soil moisture mapping using Landsat 8

\begin{tabular}{lc}
\hline \multicolumn{1}{c}{ Data } & \multicolumn{1}{c}{ Regression equation } \\
\hline March-2015 & $\mathrm{SM}=1.391554+-0.033167^{*} \mathrm{NDVI}$ \\
May-2015 & $\mathrm{SM}=-1.277810+0.069841^{*} \mathrm{NDVI}$ \\
June-2016 & $\mathrm{SM}=-0.103026+-0.001294^{*} \mathrm{NDVI}$ \\
August-2016 & $\mathrm{SM}=1.153005+-0.024250^{*} \mathrm{NDVI}$ \\
March-2017 & $\mathrm{SM}=1.382796+-0.032327^{*} \mathrm{NDVI}$ \\
\hline
\end{tabular}

matrix to create a-band image with the first 3 bands containing the majority of the useful information. The first three bands created are generally held to represent Brightness, Greenness, and Wetness (Anderson and Tamblyn 2015). The Table 3 below is showing the coefficient which is using to calculate tasseled cap transformation.

Study soil moisture also could be done by calculating wetness, greenness, and brightness using tasseled cap transformation. TCT has correlated in the brightness and the greenness values correspond to the paddy plant in the field.

\section{Results}

\subsection{NDWI}

The results of NDWI 1 and 2 shown the distribution of water content in Indramayu District has a different distribution in March 2015 (0315), May, 2015 (0515), June 2016 (0616), August 2016 (0816), and March 2017 (0317). NDWI 1 has the widest range than NDWI 2 but has a similar model. Where at May 2015 has the highest value than another's months.

Soil moisture change could be explained based on the calculation result of NDWI according to both proposed formulas. Based on both calculated NDWI, fifth satellite Landsat 8 data give a different level of water content. But in general, from third to the fifth month on the 2015 present a highest different water content. It showed by the low NDWI value. This is means, in 2015 would be the driest year in Indramayu District. The statistic of both NDWI 1 and 2, and the NDWI map results can be seen in Table 4, Figure 3 and Figure 4.

NDWI 1, in general provides a highest value than NDWI 2. It makes sense, because of NDWI 2 has designed to detect the water body. In this study, water body is limited to the water supply for irrigation systems. In fact, whole area or paddy field are larger than the water body in Indramayu District. So this is the reason why the values of NDWI 1 is higher than NDWI 2. The NDWI 1 was designed to detect the water content in the leaves. In this study, the whole area of paddy field already harvested.

Tabel 3. The coefficient of TCT for Landsat 8 OLI calibrated bands images

\begin{tabular}{lrrrrrr}
\hline \multicolumn{1}{c}{ Data } & Band 2 & Band 3 & Band 4 & Band 5 & Band 6 & Band 7 \\
\hline Brightness & 0.3029 & 0.2786 & 0.4733 & 0.5599 & 0.508 & 0.1872 \\
Greenness & -0.2941 & -0.243 & -0.5424 & 0.7276 & 0.0713 & -0.1608 \\
Wetness & 0.1511 & 0.1973 & 0.3283 & 0.3407 & -0.7117 & -0.4559 \\
\hline
\end{tabular}


Tabel 4. NDWI statistic values using Gao (1996) and McFeeters (1996) methods

\begin{tabular}{|c|c|c|c|c|c|c|c|c|c|c|}
\hline \multicolumn{11}{|c|}{ Normalized difference water index } \\
\hline & \multicolumn{5}{|c|}{ Gao (1996) } & \multicolumn{5}{|c|}{ McFeeters (1996) } \\
\hline & 0315 & 0515 & 0616 & 0816 & 0317 & 0315 & 0515 & 0616 & 0816 & 0317 \\
\hline Min & -1.093 & -1.105 & -0.607 & -0.766 & -0.614 & -0.844 & -0.766 & -0.722 & -0.726 & -0.614 \\
\hline Max & 0.899 & 2.057 & 1.070 & 1.100 & 1.222 & 1.050 & 1.672 & 0.931 & 0.684 & 1.222 \\
\hline Mean & & 0.259 & 0.358 & 0.261 & 0.274 & & -0.332 & -0.303 & -0.403 & 0.274 \\
\hline
\end{tabular}
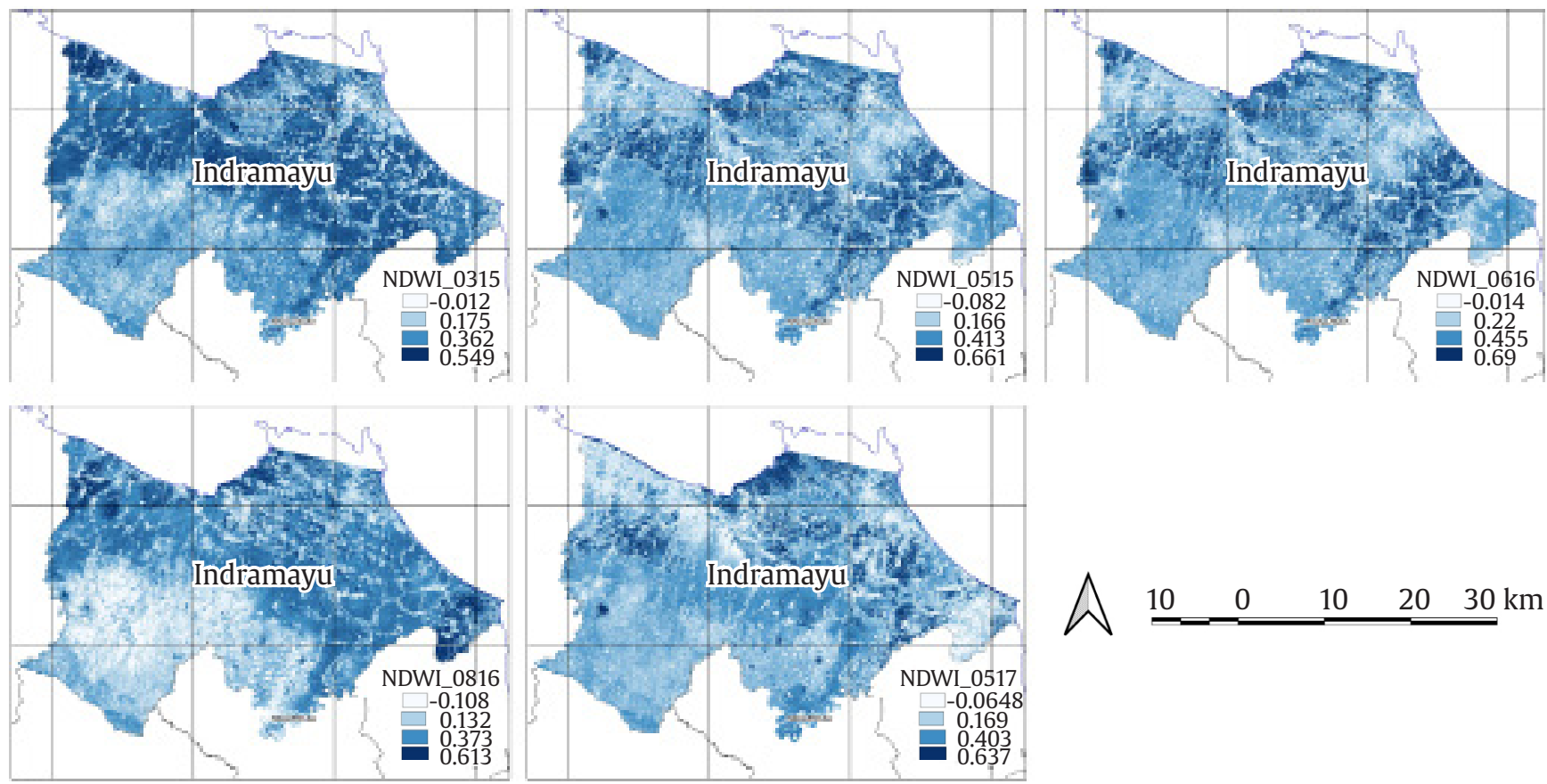

Figure 3. A multi-temporal of NDWI map calculated using Gao method (1996). It shows the maps from March-May 2015, June-August 2016, and March 2017 from left to right respectively. In March 2015, the dry area is dominated in south part and the middle part has a high water content; in May 2015, the dry area is distributed to all study area and the driest area is in west part; in June 2016, the dry area is dominated in south and north part, but some parts still have a high water content; in August 2016, the dry area is dominated in south-west part, this condition is similar to March 2015; in March 2017. The dry area is distributed to all study area, this condition is similar to May 2015, but the condition is driest in May 2015 than March 2017

\subsection{Linear Soil Moisture}

Both NDVI and LST required to obtain the soil moisture. Both information is obtained from reflectance value of near-infrared (NIR) band and red band, and thermal band 10 of Landsat 8 . The physical explanation regarding these estimation result, when the soil moisture exists on some level, it will support to paddy to growth. In the same time, the land surface temperature gives a specific characteristic to the soil to keep the water on it. Preliminary analysis will be conducted by eliminated non agricultural pixel and cloud pixel based on NDVI value. It is important to perform this procedure, because of the limitation of using the optical data, when the study area is covered by cloud.

Values of linear soil moisture indicates both wetness and drought level of soil in paddy field. Higher value indicate paddy plant is cultivated in a wet condition and the lower value means in dried land. The results of linear soil moisture shown that the distribution of soil moisture has a different condition in March 2015 (0315), May 2015 (0515), June 2016 (0616), August 2016 (0816) and March 2017 (0317). The lowest soil moisture condition was happened in June 2016. The highest soil moisture condition happened in August 2016. The distribution of soil moisture index resulted from the linear regression between NDVI and LST can be seen in Figure 5.

\subsection{Tasseled Cap Transformation}

Study soil moisture also could be done by calculating wetness, greenness, and brightness using tasseled cap transformation. The relationship of this method in assessing the soil moisture in the paddy field in 

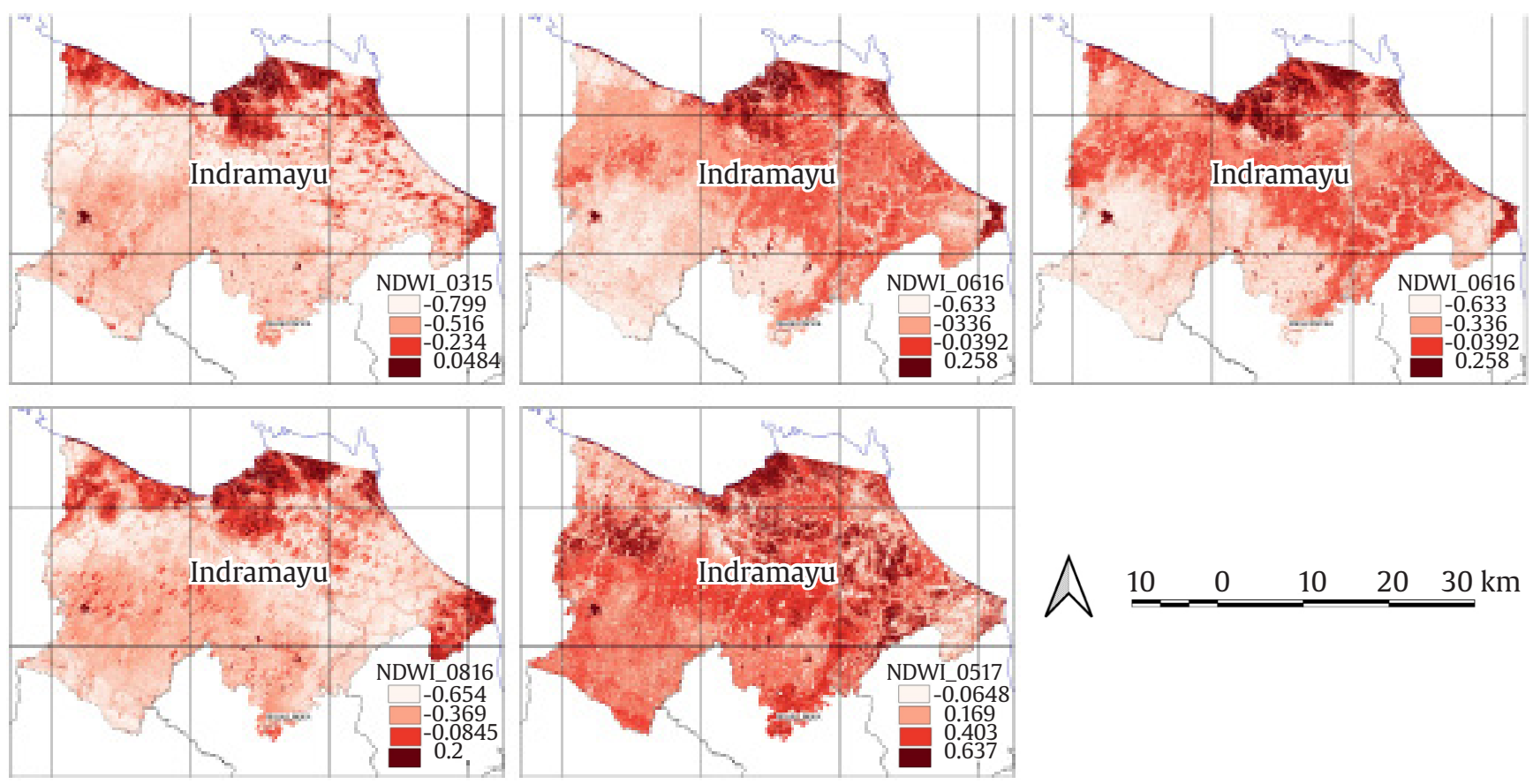

Figure 4. A multi-temporal of NDWI 2 map calculated using McFeeters method (1996). It shows the maps from MarchMay 2015, June- August 2016, and March 2017 from left to right respectively. The results are similar to NDWI 1. In March 2015, the dry area is dominated in south part and the middle part has a high water content; in May 2015, the dry area is distributed to all areas and the driest area is in west part, but some parts near river and sea still have a high water content; in June 2016, the dry area is dominated in south and north part, but some parts still have a high water content; in August 2016, the dry area is dominated in south-west part, this condition is similar to March 2015; in March 2017. The dry area is distributed to all study area, this condition is similar to May 2015, but the condition is driest in May 2015 than March 2017

Indramayu region is located in the brightness value and the greenness corresponds to the paddy plant in the field. The RGB composite of Brightness (R), Greenness ( $G$ ) and Wetness (B) resulted of the tasseled cap transformation from Landsat 8 data acquired in March 2015 shows the highest content of water (light green), the lowest soil moisture (dark blue) and moderate (tosca). The lowest level of soil moisture indicates the built-up area and the moderate indicate farmland. Actually, this is enough to show a qualitative correlation between soil moisture condition in a paddy field based on it landcover (Figure 6).

\section{Discussion}

Soil moisture change could explain based on calculation results of NDWI, Linear Soil Moisture (LSM), and Tasseled Cap Transformation (TCT). NDWI has explained that the driest year occurs in 2015. This condition is explained by the greatest NDWI value using Gao (1996) and McFeeters (1996) methods. Like NDWI, soil moisture conditions using LST in 2015 are low. However, in June 2016 soil moisture conditions are more uniform in all locations. TCT results are still relatively similar to NDWI and LST results. Where the value of wetness in 2015 is lower than in other years. The graph in Figure 7 is showing the rate of soil moisture exchange based on NDWI, LST, and TCT.

To compare the estimation result of soil moisture, we used six plot random sampling points from the research conducted by Nurtyawan (2016) in the same areas. This section is providing an explanation of the condition of soil moisture comparison between estimation resulted from RADAR and optical sensor of Landsat 8 OLI/TIRS results. It also provides a justification of estimation result quality. Plot 1 to plot 6 is located on a paddy field in Indramayu region. The value of soil moisture was conducted using radar data.

We compared six soil moisture data from two different radar data with the same month. This is in June and August 2014. We provided six different analyses and explained the effectiveness using optical data in estimating soil moisture change in the paddy field. In the first plot, all the optical soil moisture is located below the soil moisture estimated by radar in August. For exemption with the Brightness of TCT are higher than another result on June. This plot is located in a 

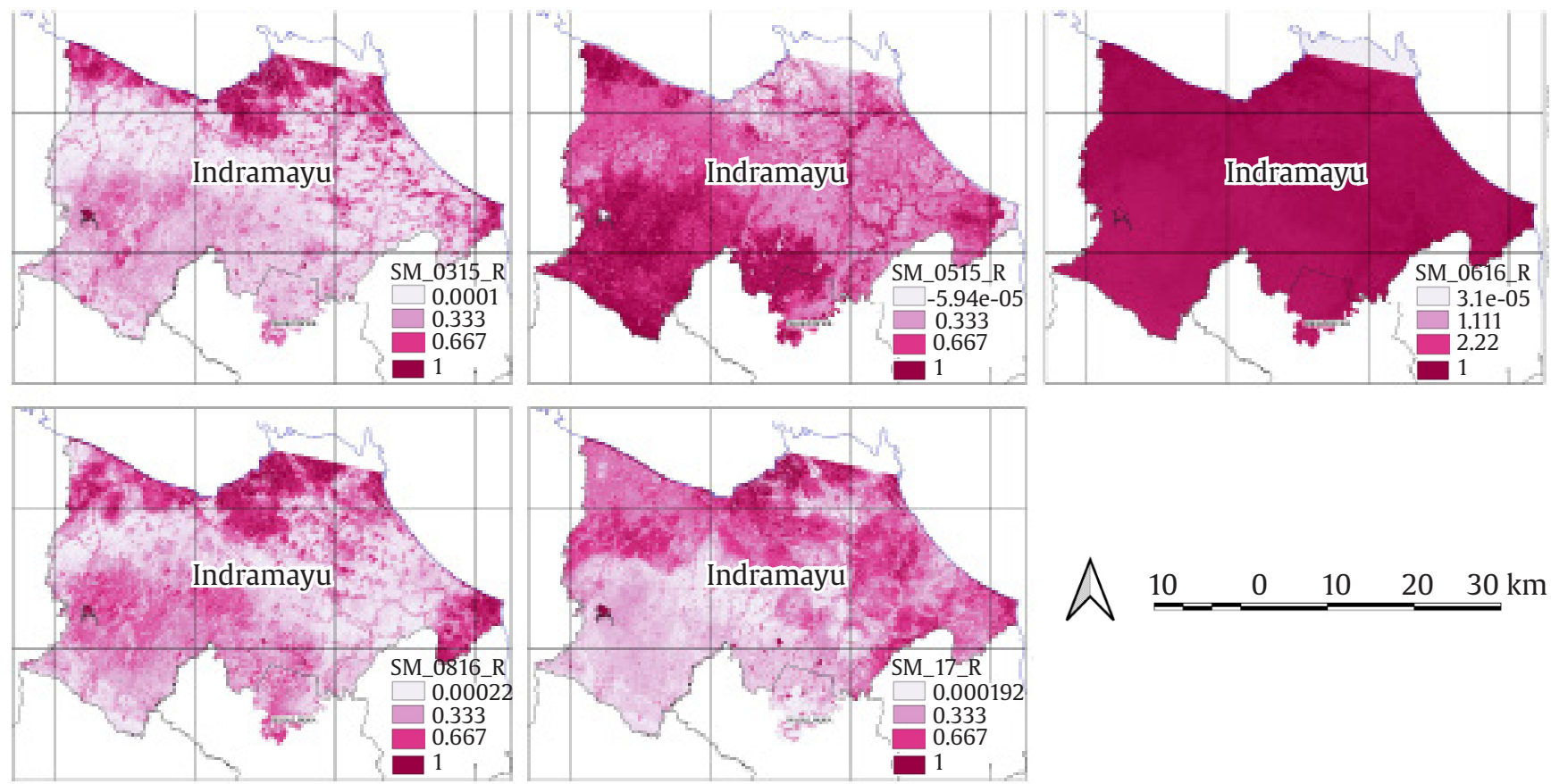

Figure 5. A multi-temporal of soil moisture index map resulted from the linear regression between NDVI and LST. It shows the maps from March-May 2015, June-August 2016, and March 2017 from left to right respectively. In March 2015, the lowest soil moisture is distributed in south area, it is be spread evenly from west to east; in May 2015, the lowest soil moisture is distributed dominantly in west area; in June 2016, almost area has a low soil moisture values; in August 2016, the lowest soil moisture is distributed in north part, the highest soil moisture is distributed in the middle part; in May 2017, the lowest soil moisture occurs locally to the north part and in the the south part is dominated by high moisture soil

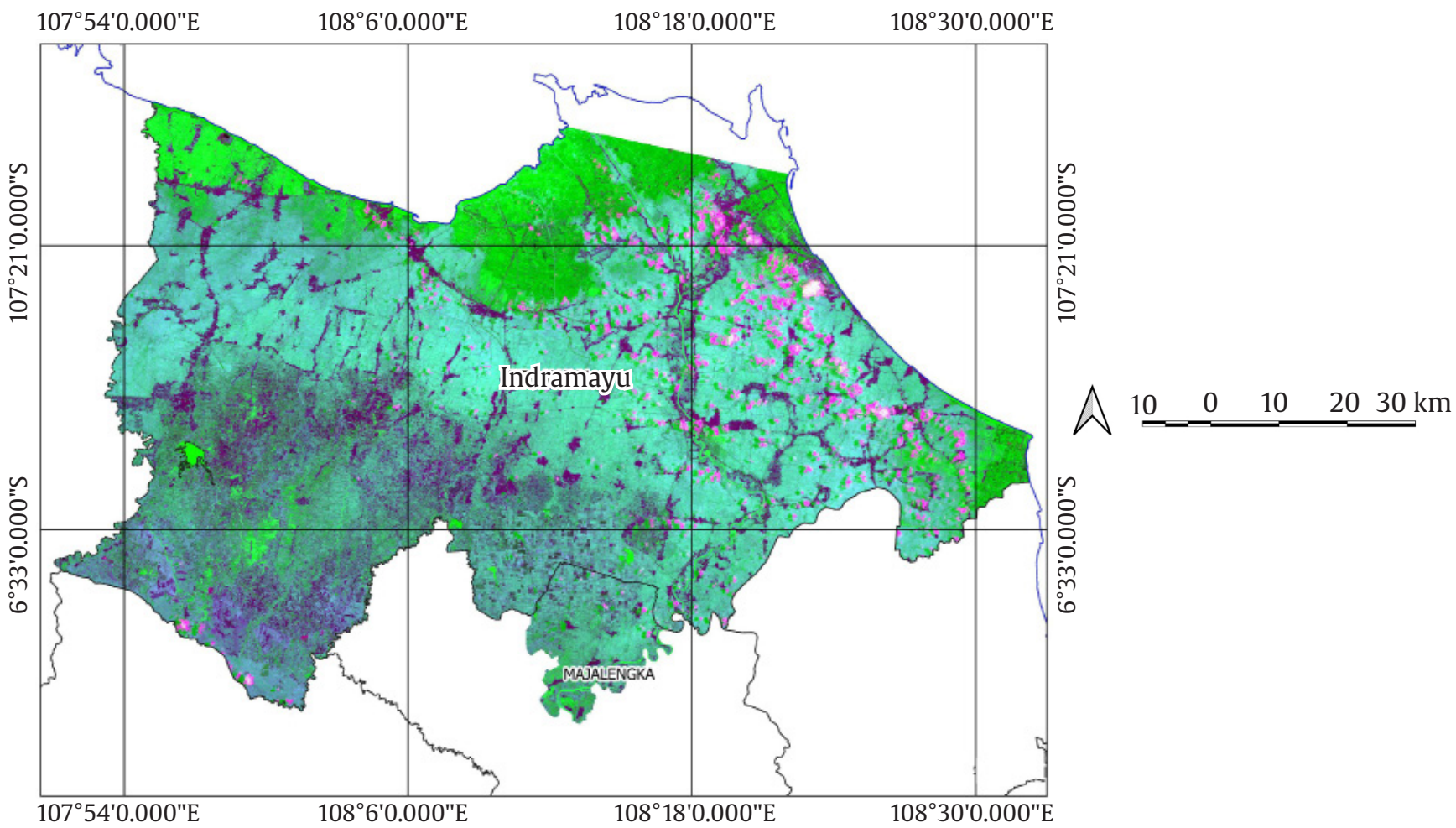

Figure 6. The RGB composite of Bightness (R), Greenness (G), and Wetness (B) resulted in the tasseled cap transformation from Landsat 8 data acquired in March 2015; light green shown the highest content of water, dark blue shown the lowest soil moisture, and tosca green shown the moderate soil moisture 

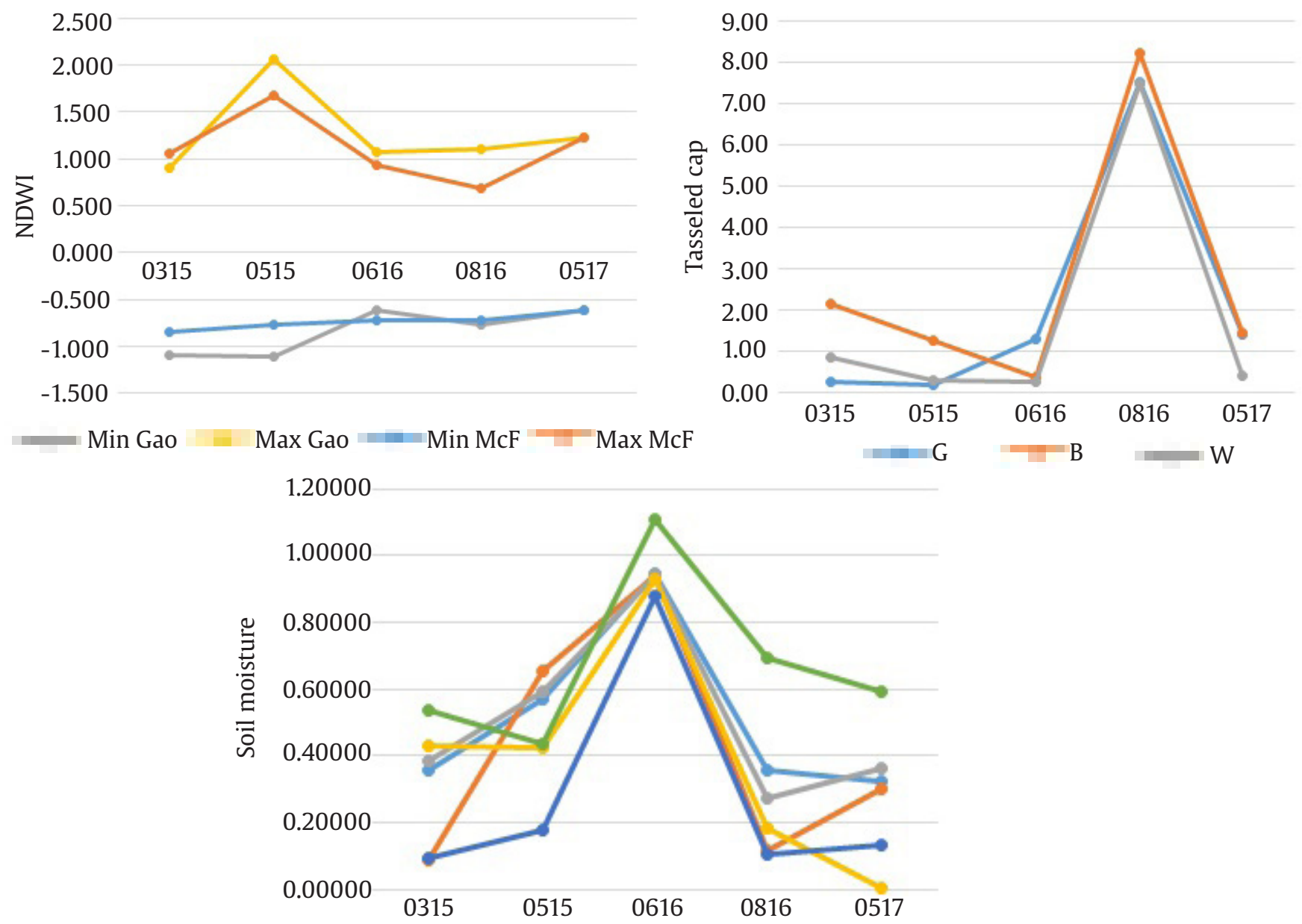

Plot $1-$ Plot $2-$ Plot $3-$ Plot $4=$ Plot $5=$ Plot 6

Figure 7. Different water content condition in paddy field using NDWI, TCT, and LSM. The minimum and maximum value graph of NDWI using Gao (1996) and McFeeters (1996) methods (left). Brightness, wetness, and greenness TCT graph from 2015 to 2017 (right). Six plot random sampling shown in June 2016 has a higher soil moisture (bottom)

paddy field with the NDVI -0.14338 (June), this means there was no paddy plant is cultivated in the paddy field and the soil has the lowest soil moisture. On the August, when the NDVI is 0.46776 the soil moisture is increasing. It could be paddy is already cultivated. The comparison of soil moisture that is resulted from Radar and Landsat data can be seen in Figure 8.

The second plot has NDVI -0.14186 and 0.67989. All the indices have given a higher estimated soil moisture than radar, especially on June, but it without paddy plant in the paddy field. On August, TC_Greeness has equal soil moisture with radar, and TC_Wetness, and TC_Brightness are a bit higher than radar. A higher NDVI indicates paddy is growing well with a good water supply. For a complete NDVI value corresponds with the soil moisture level on each plot is provided in Table 5.

\section{Conclusion}

The study for soil moisture estimation using optical satellite data is possible to do by using NDVI, tasseled cap transformation and LSM (Linear soil moisture) with considering in the characteristic of land use and land cover types. In this study, estimated soil moisture will be different depend on the NDVI value. Since NDVI value indicates the land cover types in the area. Lower means no or without paddy plant and higher means, paddy plant exists. The used of tasseled cap information is better to provide an estimation result closely with the radar resulted. In the other hand, the use of the new method of Linear Soil Moisture (LSM) will be the best if it applied into the area with a homogeneous cover type, such as paddy. 


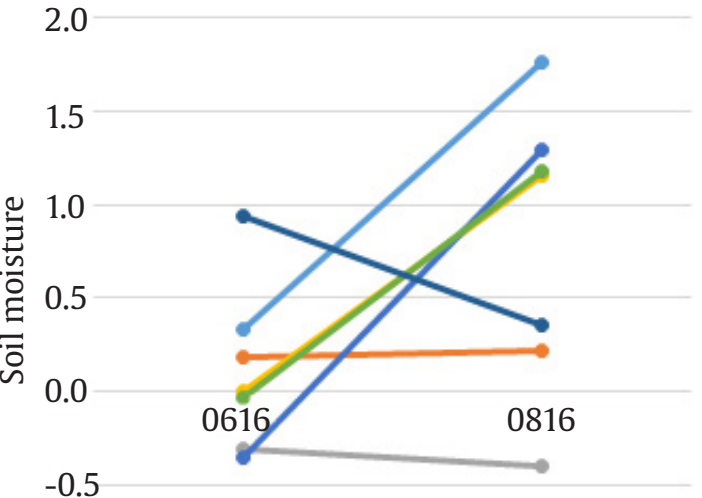

$-1.0$

-Plot 1 NDWI_Gao NDWI_McFeteer

$=$ Tc_green $=$ Tc_bright $=$ Tc_wet $=$ SM

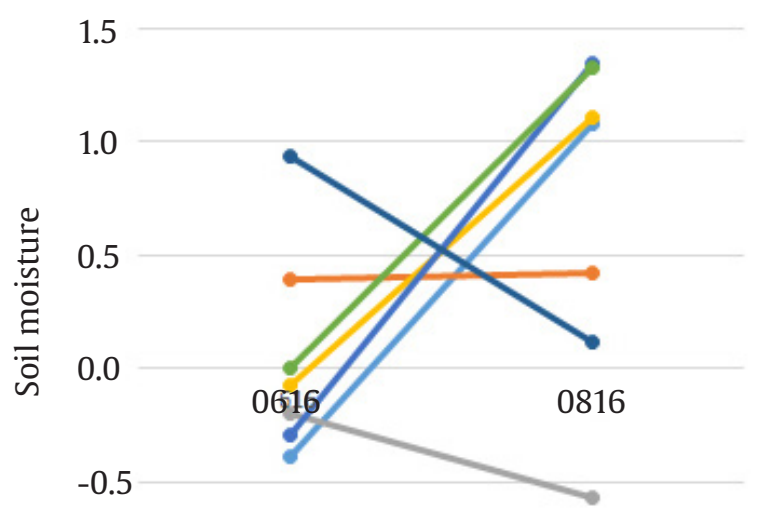

$-1.0$

$=$ Plot $2=$ NDWI_Gao NDWI_McFeteer

$=$ Tc_green - Tc_bright $=$ Tc_wet $=$ SM

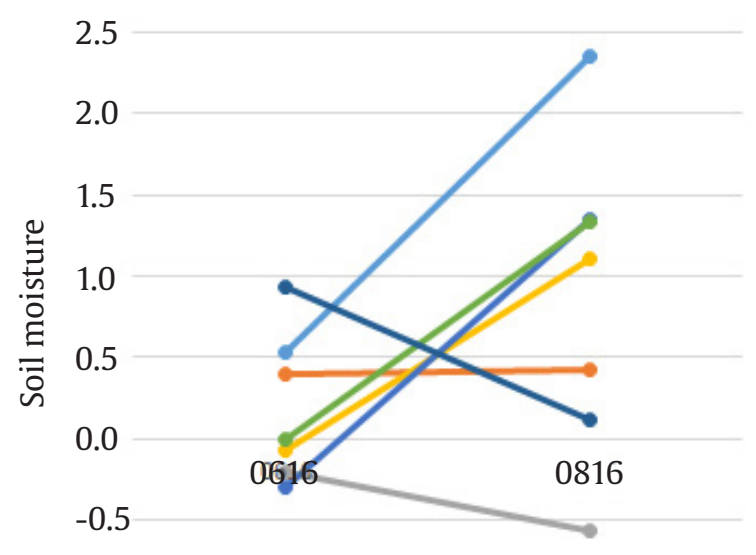

$-1.0$

-Plot 3 NDWI_Gao NDWI_McFeteer

$=$ Tc_green + Tc_bright $=$ Tc_wet $=S M$
2.0

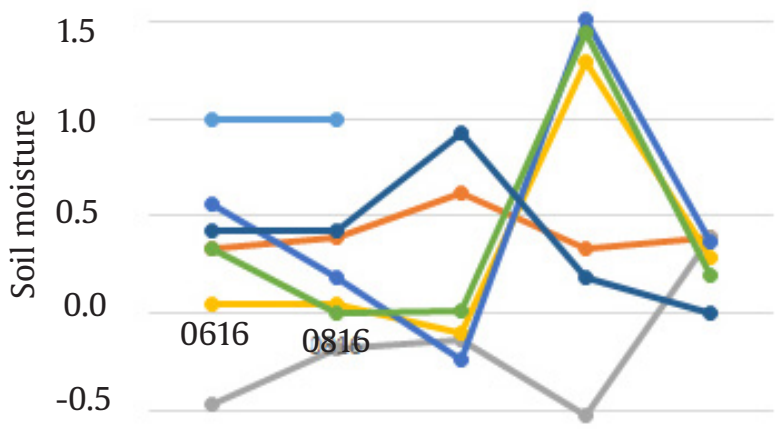

$-1.0$

$=$ Plot $4=$ NDWI_Gao NDWI_McFeteer

- Tc_green - Tc_bright $=$ Tc_wet $\cong$ SM

2.0

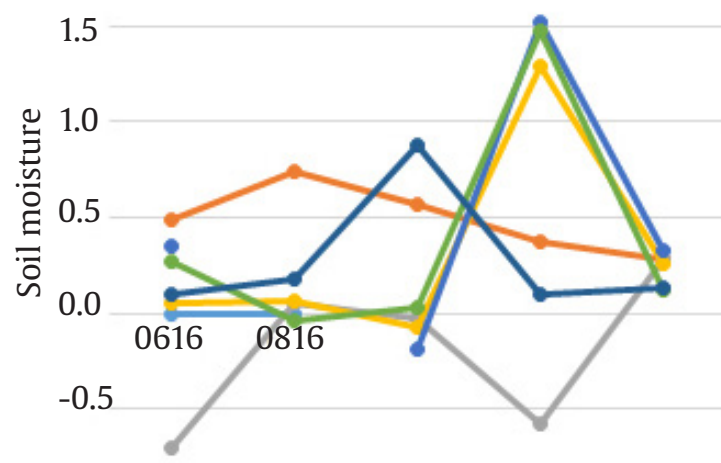

$-1.0$

$=$ Plot 5 NDWI_Gao NDWI_McFeteer

- Tc_green - Tc_bright $=$ Tc_wet $=S M$

2.0

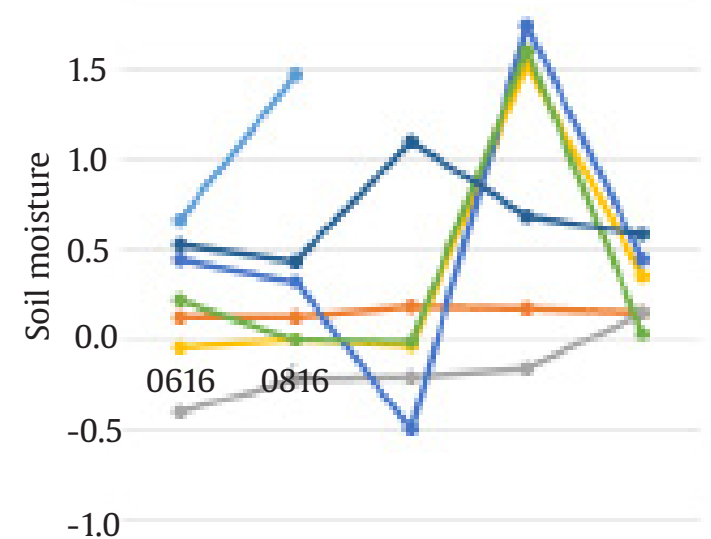

-Plot 6 NDWI_Gao NDWI_McFeteer

- Tc_green - Tc_bright $=$ Tc_wet $\cong$ SM

Figure 8. Soil moisture comparison using radar and optical data in six plots 
Table 5. Estimation values comparison of the soil moisture and NDVI. The * indicates the higher soil moisture and NDVI

\begin{tabular}{|c|c|c|c|c|c|c|c|c|c|c|}
\hline 0315 & 0515 & 0616 & 0816 & 0517 & & 0315 & 0515 & 0616 & 0816 & 0517 \\
\hline 0.22638 & 0.18043 & 0.18641 & 0.21220 & 0.17538 & NDWI_Gao & 0.33718 & 0.38820 & $0.62247^{*}$ & 0.33390 & 0.38887 \\
\hline .54474 & -0.32358 & .30713 & -0.40355 & 0.17538 & NDWI_McFeteer & -0.47342 & -0.18052 & -0.14103 & -0.52100 & 0.38887 \\
\hline 02401 & & 00539 & 1.15873* & 0.28811 & TC_Green & & & & & \\
\hline 0.32192 & 560 & -0.35237 & $1.28796^{*}$ & 0.34892 & TC_Bright & $0.55829 *$ & 0.18574 & -0.24 & $1.51557^{*}$ & 0.36891 \\
\hline 0.19046 & 0.02387 & -0.03263 & $1.17676^{*}$ & 0.08921 & TC_Wet & 0.33389 & -0.00244 & 0.01083 & $1.44445^{*}$ & 0.19347 \\
\hline 0.35977 & $0.56938^{*}$ & 0.94399* & 0.35716 & 0.32644 & SM & 0.42 & 0.42218 & $0.92877^{*}$ & 0.18199 & 0.00388 \\
\hline $.53407^{*}$ & 0.35301 & $\begin{array}{c}0.330982 \\
-0.14338\end{array}$ & $\begin{array}{l}1.76642^{*} \\
0.46776\end{array}$ & $0.48056^{*}$ & $\begin{array}{l}\text { Plot } 1 \text { NDVI } \\
\end{array}$ & $0.47291^{*}$ & 0.22118 & $\begin{array}{l}1^{*} \\
-0.13867\end{array}$ & $\begin{array}{l}1^{*} \\
0.62090^{*}\end{array}$ & 0.73979* \\
\hline $48898^{*}$ & 0.28684 & 0.39319 & 0.42624 & 0.33144 & NDWI_Gao & $0.49282^{*}$ & $0.73842^{*}$ & & & 0.28042 \\
\hline 71921 & -0.38746 & -0.19850 & -0.56686 & 0.33144 & NDWI_McFetee & 26 & 0.05650 & & -0.57968 & 0.28042 \\
\hline 0.05022 & 0.02330 & -0.07468 & $1.10735^{*}$ & 0.21595 & TC_Green & 0.04846 & 0.06576 & -0.07 & $1.29284^{*}$ & 0.26341 \\
\hline 38161 & 0.20430 & -0.28961 & $1.34352^{*}$ & 0.27804 & TC_Bright & 0.34732 & & & $1.52170^{*}$ & 0.32645 \\
\hline 30376 & 0.04757 & -0.0 & $1.32816^{*}$ & 0.07207 & TC_Wet & 0.27483 & -0.03276 & 0.02 & $1.46921^{*}$ & 0.12486 \\
\hline 693 & $0.65344^{*}$ & $0.93908^{*}$ & 0.11452 & 0.29907 & $\overline{S M}$ & 0.09387 & 0.17665 & $0.87816^{*}$ & 0.10452 & 0.13599 \\
\hline $0.77897^{*}$ & 0.42829 & $\begin{array}{l}-0.38903 \\
-0.14186\end{array}$ & $\begin{array}{l}1.084621^{*} \\
0.67989^{*}\end{array}$ & $0.50256^{*}$ & Plot 2 NDVI & $0.77274^{*}$ & 0.00128 & & $\begin{array}{l}0 \\
0.68863 *\end{array}$ & 0.63362 \\
\hline 43110 & & & & & NDWI_Gao & & & & & \\
\hline & -0.330 & & & & NDWI_McFete & & & & & 0.15201 \\
\hline 02282 & 0.036 & -0.0 & & & & 31 & -0. & & $134^{*}$ & 0.36236 \\
\hline 13706 & 0.22757 & -0.33 & $1.35226^{*}$ & 0.30020 & TC_Bright & 0.44969 & & & $1.74734^{*}$ & 0.44639 \\
\hline 0.07952 & 0.02880 & -0.04035 & $1.29243^{*}$ & 0.06784 & TC_Wet & 0.22126 & -0.00073 & -0.00290 & 1.61133* & 0.04140 \\
\hline 38361 & $0.59243^{*}$ & $0.93888^{*}$ & 0.27612 & 0.36203 & SM & $0.53425^{*}$ & 0.43606 & $1.10838^{*}$ & $0.69509^{*}$ & 0.59121 \\
\hline & & & & & Plot $3 \quad$ Plot 6 & & & 0.670312 & & \\
\hline $51268^{*}$ & 37366 & -0.14180 & $0.53861^{*}$ & 0.45195 & NDVI & 0.37747 & 361 & -0.19433 & 0.17233 & \\
\hline
\end{tabular}

\section{References}

Ali et al. 2017. Retrieval of specific leaf area from Landsat-8 surface reflectance data using statistical and physical models. IEEE Journal of Selected Topics in Applied Earth Observations and Remote Sensing 10:3529-3536. DOI:10.1109/JSTARS.2017.2690623

Anderson I, Tamblyn C. 2015. Tasseled Cap Transformation for Landsat 8. Available at: http://community. hexagongeospatial.com/t5/tkb/articleprintpage/tkb-id/ KS_SpatialModeler_Analytical Recipes/article-id/29 [Date accessed: 10 October 2017]

Baig MHA et al. 2014. Derivation of a tasselled cap transformation based on Landsat 8 at satellite reflectance. Remote Sensing Letters 5:423-431.

Darojati NW. 2015. Monitoring Drought and Risk of Drought Analysis in Indramayu [Thesis]. Bogor, Indonesia: Graduate Program of Bogor Agriculture University.

De Datta SKD. 1981. Principles and Practices of Rice Production. Los Banos: John Willey and Sons.

Gao BC. 1996. NDWI-a normalized difference water index for remote sensing of vegetation liquid water from Space. Remote Sensing Environment 58:257-266.

Humboldt State University. 2016. Introduction to Remote Sensing. Humboldt State Geospatial Online. available at: http://gsp.humboldt.edu/olm_2015/Courses/ GSP_216_Online/lesson41/radiometric.html [Date accessed: 11 October 2017]

Kogan F. 1995. Application of vegetation index and brightness temperature for drought detection. Journal Advances in Space Research 15:91-100.
Li Z et al. 2015. Assessments of drought on vegetation in China with the optimal time scales of the climatic drought index. International Journal of Environmental Research and Public Health 12:7615-7634.

McFeeters SK. 1996. The use of the normalized difference water index (NDWI) in the delineation of water feature. International Journal of Remote Sensing 17:1425-1432.

McKee TB et al. 1993. The relationship of drought frequency and duration to time scales. In: Proceedings of the Eighth Conference on Applied Climatology. Anaheim: American Meteorological Society. pp. 179-184.

Nurtyawan Ret al. 2016. Modeling surface roughness to estimate surface moisture using radarsat-2 quad polarimetric SAR data. Journal of Physics: Conference Series 739:1-9.

Palmer WC. 1965. Meteorological Drought; U.S. Department of CommerceWeatherBureau.WashingtonDC: ResearchPaper:

Pandolfo A et al. 2017. Using Landsat TM Data for Soil Moisture Mapping, Leicester: Lecture Notes. Available at: https://www.researchgate.net/file.PostFileLoader. html? id=5927fe8f615e271 de66a3990\&assetKey= AS\%3A498207345713153\%401495793295111 [Date accessed: 12 October 2017]

Rojas et al. 2011. Assessing drought probability for agricultural areas in Africa with coarse resolution remote sensing imagery. Remote Sensing of Environment 115:343-352. DOI:10.1016/j.rse.2010.09.006

Vicente-Serrano SM et al. 2010. A multiscalar drought index sensitive to global warming: the standardized precipitation evapotranspiration index. J Clim 23:1696-1718. 
Sparavigna AC. 2015. Recurrence Plots for the analysis of Vegetation Health Index ( VHI). Available at: https:// hal.archives-ouvertes.fr/hal-02265908 [Date accessed: 18 October 2017]

USGS 2017. Using the USGS Landsat 8 Product. Available at: https://landsat.usgs.gov/using-usgs-landsat-8-product [Date accessed: 20 October 2017]
Wang LI. 2009. Satellite remote sensing applications for surface soil moisture monitoring: a review. Frontiers of Earth Science in China 3:237-247.

Zeng Y et al. 2004. Assessment of soil moisture using Landsat $\mathrm{ETM}+$ temperature/vegetation index in semiarid environment. In: International Geoscience and Remote Sensing Symposium. Anchorage: IGARSS 2004. 